\title{
SÉRIE ESTRUTURAL
}

\author{
STRUCTURAL SERIES
}

Lucas Costa ${ }^{1}$

Em meu trabalho, os procedimentos utilizados estão às voltas de um certo raciocínio escultórico, mas que por sua vez, necessita de outras linguagens (pintura, instalação, fotografia e vídeo) para se materializar. O vocabulário da arquitetura - e de outras áreas correlatas à construção civil - também influenciam meu processo criativo de forma bastante decisiva, pois além de fazerem parte de um contexto de ação, também inserem dados fundamentais para sua reflexão. Devido ao modo de construção desses trabalhos, a instabilidade - e sua consequente tensão (física e/ou psicológica) - se apresenta como característica central de minha pesquisa.

No projeto artístico "Série Estrutural", a tarefa de suportar uma pilha de blocos de concreto através da capacidade muscular foi a atividade central de minhas ações no ambiente da construção civil. Esta atividade possibilitou-me criar configurações temporárias, que deram início a essa série de trabalhos em fotografia, iniciado em 2013.

O projeto consiste na criação de elementos estruturais (viga e/ou coluna) nesses espaços, onde o meu corpo sustenta os materiais construtivos (blocos de concreto) inseridos na edificação. Desta forma, a atividade opera em um limiar, no qual o posicionamento dos blocos de concreto, depende da aplicação de força e resistência física em manter aquela configuração, provocando certa instabilidade na contextura que, a priori, é caracterizada pela permanência e segurança - se pensarmos na função desses elementos na área da arquitetura. Através dessas condições fisiológicas impostas ao projeto "Série Estrutural", deflagra-se o fenômeno instável advindo desse embate entre corpo e arquitetura.

Construir um momento de integridade entre a estrutura e eu é a experiência basilar dessas ações, e habitar esses ambientes, para mim, é fazer parte de sua fundação. Por um curto espaço de tempo - registrado em fotografia - o corpo e os materiais funcionam como arquitetura.

\footnotetext{
${ }^{1}$ Universidade Estadual Paulista Júlio de Mesquita Filho, São Paulo-SP, Brasil.
} 


\section{SÉRIE ESTRUTURAL}

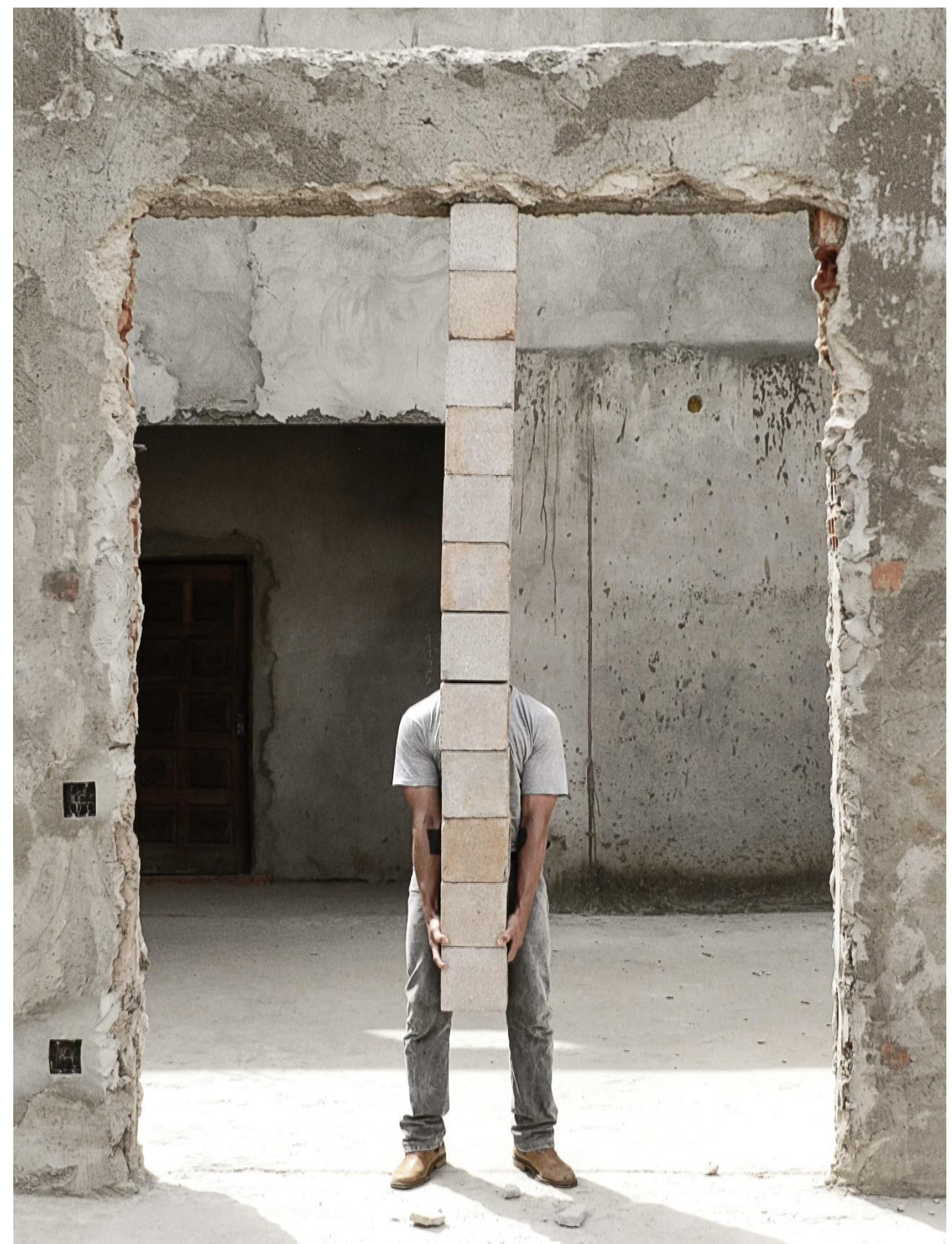

Coluna Viva, 2013-14 | Série Estrutural - Ação orientada para fotografia (fotoperformance), Hortolândia-SP 


\section{SÉRIE ESTRUTURAL}

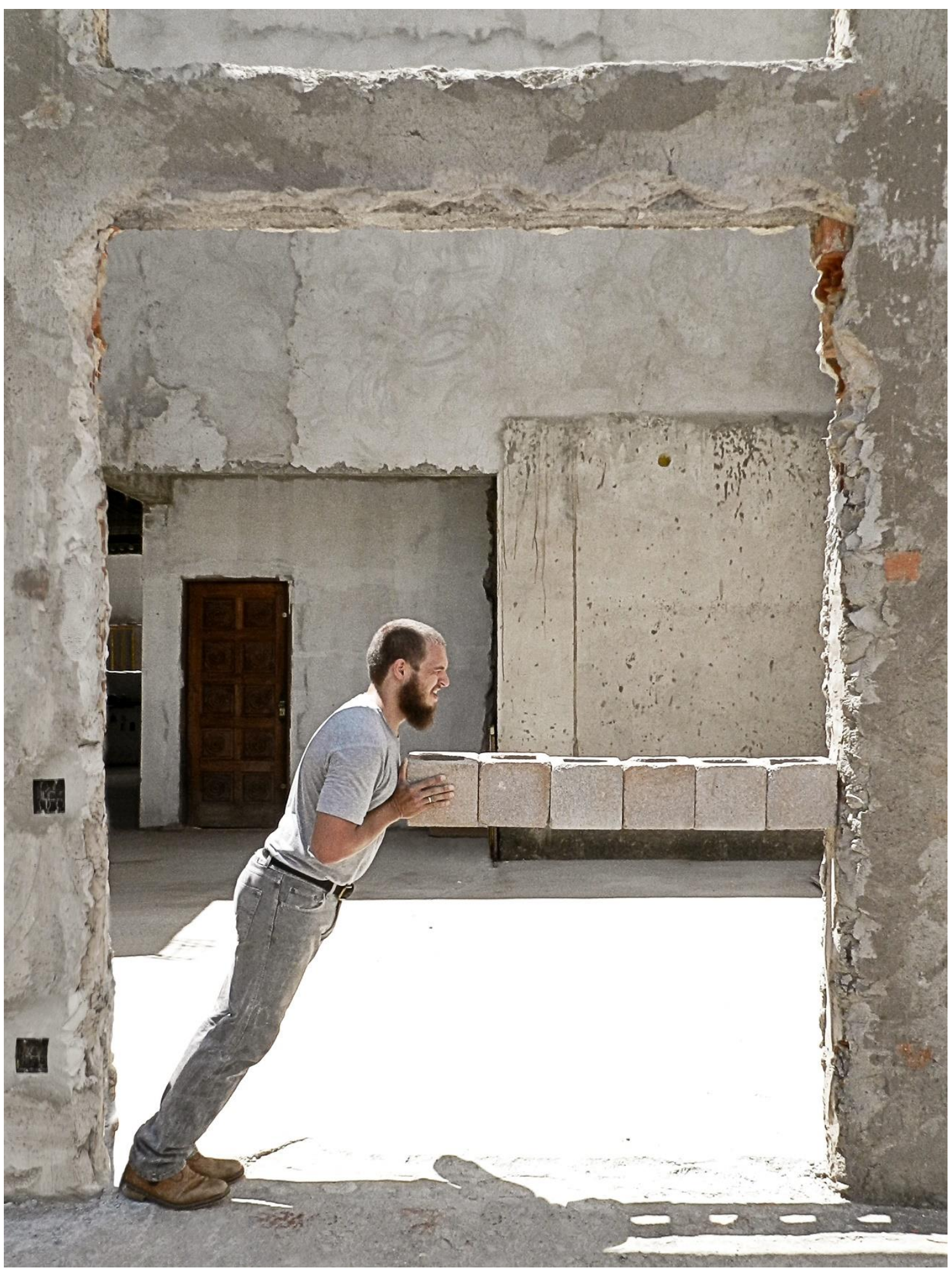

Viga Viva, 2013-14 | Série Estrutural - Ação orientada para fotografia (fotoperformance), Hortolândia-SP 

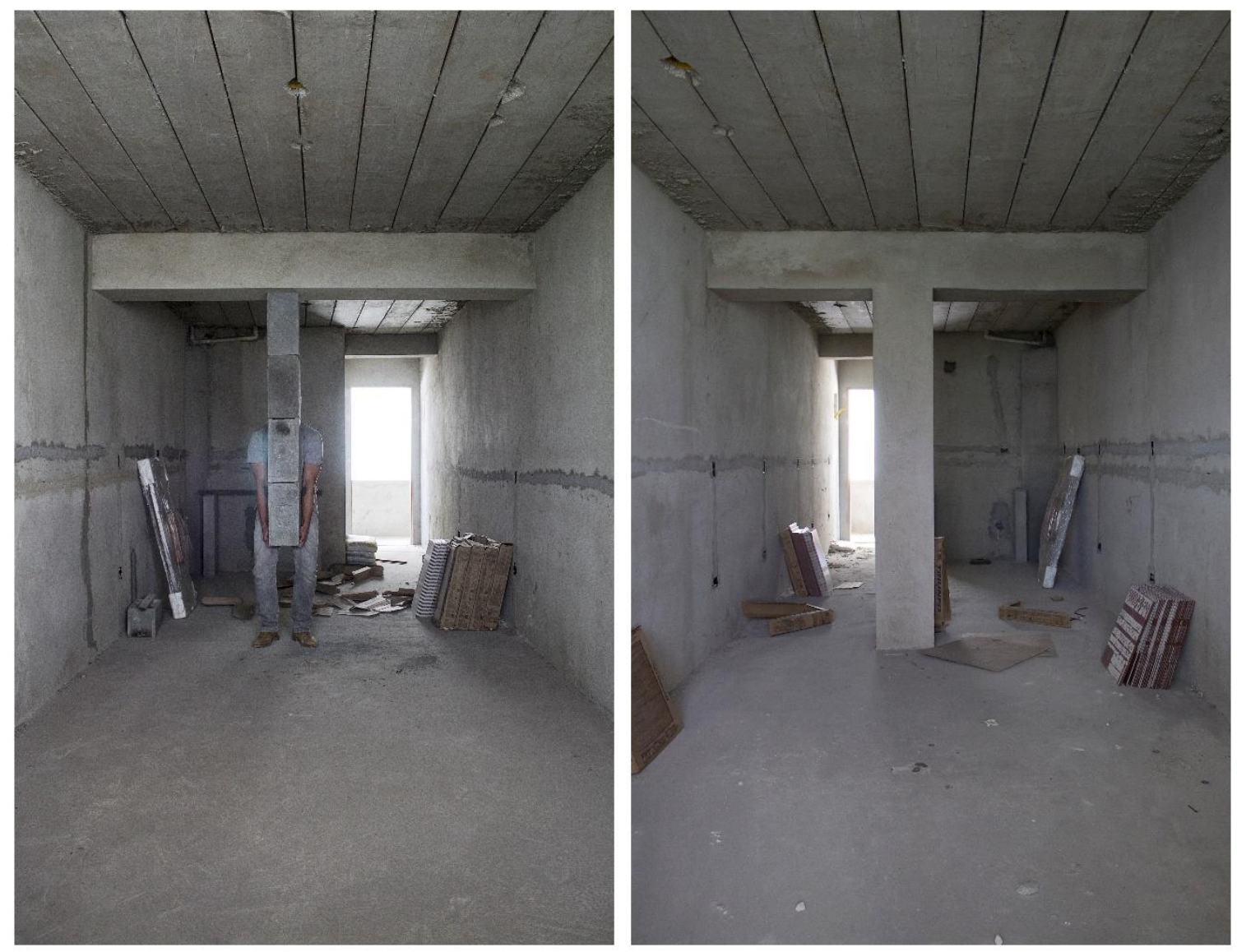

Coluna Viva II, 2014 | Série Estrutural - Ação orientada para fotografia (fotoperformance), São Paulo-SP

\section{Sobre o autor}

Lucas Costa é artista e professor universitário. Possui mestrado em "Processos e Procedimentos Artísticos" (2015) pela Unesp - com bolsa CAPES de pesquisa - e graduação em Artes Visuais (2012) pela mesma universidade - com bolsa de Iniciação Científica (CNPq). Atualmente é doutorando em Artes Visuais pela Unesp, com bolsa CAPES, sob orientação do Prof. Dr. Agnus Valente. É professor da Faculdade de Administração e Artes de Limeira (FAAL). E-mail: lucas_brs@hotmail.com. 